\title{
Melatonin Protects Intervertebral Disc from Degeneration by Improving Cell Survival and Function via Activation of the ERK1/2 Signaling Pathway
}

\author{
Jun Ge, ${ }^{1}$ Quan Zhou, ${ }^{2}$ Junjie Niu, ${ }^{1}$ Yingjie Wang, ${ }^{1}$ Qi Yan, ${ }^{1}$ Cenhao Wu, ${ }^{1}$ Jiale Qian, ${ }^{1}$ \\ Huilin Yang $\mathbb{D}^{1}{ }^{1}$ and Jun Zou $\mathbb{D}^{1}$ \\ ${ }^{1}$ Department of Orthopaedic Surgery, The First Affiliated Hospital of Soochow University, Suzhou, Jiangsu 215006, China \\ ${ }^{2}$ Department of Orthopedics Surgery, The Affiliated Huai'an Hospital of Xuzhou Medical University, Huai'an, Jiangsu 223002, China \\ Correspondence should be addressed to Jun Zou; jzou@suda.edu.cn
}

Received 23 August 2019; Revised 18 October 2019; Accepted 11 November 2019; Published 2 December 2019

Academic Editor: Antonio Desmond McCarthy

Copyright (C) 2019 Jun Ge et al. This is an open access article distributed under the Creative Commons Attribution License, which permits unrestricted use, distribution, and reproduction in any medium, provided the original work is properly cited.

\begin{abstract}
Melatonin, a neuroendocrine hormone secreted by the pineal body, has a positive effect on intervertebral disc degeneration. The present study is aimed at investigating the biological role of melatonin in intervertebral disc degeneration and its underlying mechanism. A human nucleus pulposus cell (NPC) line was exposed to melatonin at different concentrations. Cell proliferation was measured by CCK-8 assay. Cell cycle and apoptosis were analyzed by flow cytometry. Western blot was performed to measure the protein expression of indicated genes. A rabbit model of intervertebral disc degeneration was established to detect the role and mechanism of melatonin on intervertebral disc degeneration. Our study showed that melatonin promoted NPC viability and inhibited cell arrest. Furthermore, melatonin treatment led to the upregulation of collagen II and aggrecan and downregulation of collagen X. Moreover, melatonin significantly elevated the activity of the ERK signaling pathway. Inhibition of the ERK1/2 signals reversed the role of melatonin in the regulation of NPCs both in vitro and in vivo. Melatonin increased NPC viability through inhibition of cell cycle arrest and apoptosis. Moreover, melatonin promoted the secretion of functional factors influencing the nucleus pulposus cell physiology and retarded cell degeneration. Our results suggest that melatonin activated the ERK1/2 signaling pathway, thereby affecting the biological properties of the intervertebral disc degeneration.
\end{abstract}

\section{Introduction}

It is predicted that up to $80 \%$ of adults in the United States would experience some form of low back pain over their lifetime, with approximately $5 \%$ of sufferers becoming chronically disabled [1]. Intervertebral disc degeneration (IDD) is considered a chief cause of low back pain [2-4].

Melatonin is a neuroendocrine hormone secreted by the pineal body and has a role in the regulation of circadian and seasonal rhythms [5]. In addition, melatonin is closely involved in the functional regulation of neuroendocrine, reproductive, immune, and cardiovascular systems [6-9]. Previous studies showed that melatonin promotes the proliferation and differentiation of osteoblasts and bone formation in the skeletal system. In contrast, melatonin inhibits osteoclast activity and reduces bone resorption.
Moreover, melatonin promotes the differentiation of bone marrow mesenchymal stem cells (BMSCs) to osteoblasts. All these biological effects of melatonin are regulated by the melatonin receptor $[4,10-12]$. In addition, the expression of MTl and MT2 melatonin receptors was observed in chondrocytes and BMSCs, suggesting that melatonin may regulate biological processes in these cells $[13,14]$.

Recently, studies on melatonin and chondrocytes have shown a closer relationship of melatonin with the skeletal system. Porcine articular chondrocytes were evaluated in vitro by Pei et al. in a pellet culture system. Their results showed that the melatonin treatment yielded chondrocyte pellets with a higher expression of chondrogenic markers both at the mRNA and protein levels. A hypertrophic marker remained low, suggesting that melatonin promoted the chondrogenic differentiation and reduced the osteogenic 
differentiation [15]. Lim et al. examined the effects of melatonin in hydrogen peroxide- $\left(\mathrm{H}_{2} \mathrm{O}_{2}-\right)$ stimulated human chondrocytes. Melatonin markedly inhibited $\mathrm{H}_{2} \mathrm{O}_{2}$-stimulated cytotoxicity, iNOS, and COX-2 protein and mRNA expression as well as their downstream products, NO and PGE. Incubation of cells with melatonin decreased $\mathrm{H}_{2} \mathrm{O}_{2}$-induced Sirtuin 1 (SIRT1) expression. SIRT1 inhibition by sirtinol or SIRT1 siRNA reversed the effects of melatonin on proinflammatory cytokines and the expression of iNOS and COX-2. In rabbits with osteoarthritis, intra-articular injection of melatonin significantly reduced cartilage degradation, which was reversed by sirtinol. This study shows that melatonin exerts cytoprotective and antiinflammatory effects in an oxidative stress-stimulated chondrocyte model and rabbit osteoarthritis model [16].

Nucleus pulposus cells (NPCs) of the intervertebral discs are chondrocyte-like cells, homologous to the chondrocytes in term of gene expression and function. In 2006, Turgut et al. [17] performed a pinealectomy on chickens, which accelerated the IDD process. Further studies [18-21] proved the positive and protective role of melatonin in the degenerative nucleus pulposus cells. Despite these encouraging reports, none of them has comprehensively demonstrated the underlying mechanisms by which melatonin triggers these positive effects of the melatonin on IDD both in vivo and in vitro, whether melatonin can be widely applied to patients with IDD or whether it has limitations and can only be applied to a few patients. The insufficient understanding on the specific therapeutic mechanisms of melatonin is bound to hinder the development of clinical applications of melatonin and the development of molecular biological treatment of IDD.

The current study is aimed at investigating the effect of melatonin on NPCs from the perspective of both cell survival and cell function and elucidating the underlying mechanism, in order to further promote the development of IDD molecular therapy.

\section{Materials and Methods}

2.1. Cell Culture. The human nucleus pulposus cell (NPC) line was purchased from ScienCell (Carlsbad, CA, USA, Cat. No.4800). Cell culture was performed as described in the protocol in our previous study [22]. Cells preserved in liquid nitrogen were quickly thawed in a preheated water bath $\left(37^{\circ} \mathrm{C}\right)$ for $2 \mathrm{~min}$. Then, the cells were washed in $5 \mathrm{~mL}$ of culture medium in a centrifuge tube. The supernatant was removed and cells were cultured in an incubator after centrifugation. When cells reached $90 \%$ confluency, they were passaged at a ratio of $1: 2$.

2.2. Determination of Cell Viability. Cell viability of NPCs was determined at $24 \mathrm{~h}$ and $96 \mathrm{~h}$ after the induction with $0.1,0.5,1,5,10,50$, and $100 \mu \mathrm{M}$ melatonin. The measurement procedure was as described in our previous study [22]: $10 \mu \mathrm{L}$ of Cell Counting Kit-8 (CCK-8) solution (Dojindo, Tokyo, Japan) was added to each well and the 96-well plates were incubated for $1 \mathrm{~h}$ at $37^{\circ} \mathrm{C}$ and $5 \% \mathrm{CO}_{2}$. After that, the supernatants were carefully aspirated. To further lyse the cells and completely dissolve the precipitates, dimethyl sulfoxide (DMSO) was added to each well and the plates were shaken for $15 \mathrm{~min}$. The absorbance was then measured at $450 \mathrm{~nm}$. The background absorbance of the medium in the absence of cells was subtracted. The experiments were independently repeated at least three times.

2.3. Analysis of Cell Cycle. Propidium iodide (PI) staining was used to analyze cell cycle distribution as described in our previous study [22]. NPCs were digested by trypsin and centrifuged at $3000 \mathrm{rpm}$ for $5 \mathrm{~min}$. Then, cells were washed in ice-cold PBS and then centrifuged. The supernatant was carefully removed and cells were fixed in $70 \%$ ice-cold ethanol at $4^{\circ} \mathrm{C}$ overnight. Cells were collected and digested in RNase $(50 \mathrm{ng} / \mathrm{mL})$. PI $(20 \mathrm{ng} / \mathrm{mL})$ was added and cells were incubated at $37^{\circ} \mathrm{C}$ for $1 \mathrm{~h}$. Finally, the cell cycle was analyzed by flow cytometry.

2.4. Analysis of Apoptotic Cells. A double-staining assay was performed using an Annexin V-FITC/PI kit to evaluate the percentage of apoptotic cells. NPCs were treated with different concentrations of melatonin for $24 \mathrm{~h}$ before harvest. We follow the protocol in our previous study [22]. The cells were washed with $4^{\circ} \mathrm{C}$ PBS prior to being resuspended in a total volume of $500 \mu \mathrm{L}$ binding buffer. Then, $5 \mu \mathrm{L}$ of Annexin V-FITC solution and $5 \mu \mathrm{L}$ of PI were added to each sample. The cell suspension was kept on ice in the dark for $5 \mathrm{~min}$. After that, the analysis was carried out by flow cytometry. Relative apoptosis rate was compared with the control group.

2.5. Western Blot Analysis. The cells were washed three times with PBS and suspended in ice-cold lysis buffer (Bio-Rad, Hercules, CA, USA). The lysates were separated by $12 \%$ SDS-PAGE, and the proteins of equal quantity were transferred to nitrocellulose membranes. Membranes were blocked with Tris-buffered saline with Tween-20 buffer (Thermo Fisher Scientific, Waltham, MA, USA) containing $5 \%$ nonfat milk (Yili, China) and incubated overnight at $4^{\circ} \mathrm{C}$ with collagen II, collagen X (Abcam, Cambridge, MA, USA), aggrecan, Bcl-2, Bax, caspase-3 (Santa Cruz, Dallas, TX, USA), p21, p27, CDK2, CDK4 (Cell Signaling Technology, Danvers, MA, USA), p-ERK1/2, and ERK1/2 (Abcam, Cambridge, MA, USA) primary antibodies. The following day, the membranes were washed and incubated with the corresponding secondary antibodies at room temperature $\left(22-28^{\circ} \mathrm{C}\right)$ for $1 \mathrm{~h}$. An enhanced chemiluminescence detection system (Thermo Scientific, MA, USA) was finally used to determine the emission of the membrane. The experiments were performed in three independent replicates. The GAPDH expression level was used as an internal control. The Western blot results were quantified with an image analyzer (Quantity One-4,2,0, Bio-Rad, Hercules, CA) and were normalized to GAPDH immunostaining. The relative protein expression was compared with the control group.

2.6. Establishment of a Rabbit Intervertebral Disc Degeneration Model. One-year-old New Zealand white rabbits, weighing $3.0-3.2 \mathrm{~kg}$, were selected $(n=15)$. The rabbits were anesthetized by intramuscular injection of ketamine and xilazine and placed in a lateral decubitus position. 
Aseptic technique was applied for all surgical procedures. Fifteen-centimeter hair over the surgical field was shaved. Through a left retroperitoneal approach, the third lumbar processus transversus (L3) was exposed and removed from the roots, resulting in the exposure of the L3/4 intervertebral disc. This disc was punctured by a 16-gauge needle to a depth of $5 \mathrm{~mm}$ from the anterolateral fiber ring for 5 seconds. The needle was then pulled out without disturbing the spinal cord. Gentamicin $(80,000 \mathrm{U})$ was used before and after the surgery. After the surgery, all the rabbits were allowed to move freely in a cage. Magnetic resonance imaging (MRI) was used four weeks after surgery to verify the establishment of the IVD model ( 0 week). After verifying the degeneration, the rabbits were randomly divided into 3 groups, including the melatonin group, the melatonin+ERK inhibitor group, and the saline group. Rabbits were conventionally exposed and their intervertebral discs were injected with $20 \mu \mathrm{L}$ saline, melatonin $(2 \mathrm{mg} / \mathrm{mL})$, and melatonin plus U0126 $(0.4 \mathrm{mg} / \mathrm{kg})$ (Sigma, St. Louis, MO, USA), into the L3/4 intervertebral disc, respectively. Then, the surgical wounds were sutured. After the injection, all the rabbits were allowed to move freely in a cage. All the experimental procedures were performed at the Laboratory Animal Center of Soochow University. All the experimental procedures were approved by the Ethics Committee of the First Affiliated Hospital of Soochow University and were carried out in strict accordance with the Declaration of Helsinki (1964) and the Laboratory Animal Guidelines for Ethical Review of Animal Welfare (GB/T35892-2018, China).

2.7. MRI Examination. MRI was performed to assess the degree of intervertebral disc degeneration at four and eight weeks after injection. Sagittal T2-weighted images were obtained using a $1.5 \mathrm{~T}$ MRI (GE HDx, Milwaukee, WI, USA). In the T2-weighted images, 5 discs ( 5 animals) per group were classified according to the modified Thompson classification from grades I to IV (I, normal; II, minimal decrease of signal intensity but obvious narrowing of high signal area; III, moderate decrease of signal intensity; and IV, severe decrease of signal intensity) [10].

2.8. Histological Examination. Rabbits were sacrificed after an eight-week MRI examination. The L3/4 intervertebral discs were harvested, fixed in 10\% neutral formaldehyde, and decalcified in 10\% EDTA for 4 weeks. The tissues were then horizontally cut into five slices, $4 \mu \mathrm{m}$ in width. After hematoxylin and eosin ( $\mathrm{H} \& \mathrm{E})$ staining, the slices were observed under a microscope. For immunohistochemistry detection, sections were incubated with primary antibodies specific to ERK (EterLife, UK), collagen II (Novus Biologicals, CO, USA), and collagen X (Biosynthesis Biotech, China). The obtained images were captured on an image analysis system and analyzed by Image Pro Plus 6.0 software (Media Cybernetics, Baltimore, MD, USA). Integrated optical density was calibrated, and the area of interest was established. The mean optical density was defined as the integrated optical density divided by area.
2.9. Statistical Analysis. All quantitative data are presented as mean \pm S.D. For parametric data, statistical analyses were performed by one-way ANOVA. For nonparametric data, the Kruskal-Wallis test was performed. Differences with values of $p<0.05$ were considered statistically significant.

\section{Results}

3.1. Melatonin Enhances NPC Viability. Initially, to investigate the effect of melatonin on nucleus pulposus cell behavior, we treated the cells with $0.1,0.5,1,5,10,50$, and $100 \mu \mathrm{M}$ melatonin for $24 \mathrm{~h}$ and $96 \mathrm{~h}$. NPC viability was analyzed using the CCK- 8 assay. The viability of NPCs showed slight but significant increases at a concentration of melatonin between $0.5 \mu \mathrm{M}$ and $5 \mu \mathrm{M}$ compared with the control group both in $24 \mathrm{~h}$ and $96 \mathrm{~h}$ (Figure 1 (a), $p<0.05$ ). In $96 \mathrm{~h}$, slight but significant increases were also detected with a concentration between $5 \mu \mathrm{M}$ and $50 \mu \mathrm{M}$ (Figure $1(\mathrm{a}), p<0.05$ ).

3.2. Melatonin Improves NPC Morphology. On the basis of these results, NPCs treated with melatonin at $0.1,1$, and $5 \mu \mathrm{M}$ were chosen for further study. Changes in their morphology were observed under a microscope. Compared with the control group, the NPC morphological changes could be observed in a dose-dependent manner. The cells changed from short and round to long spindle or polygonal with the treatment of melatonin (Figure 1(b)).

3.3. Melatonin Reduces NPC Cell Cycle Arrest and Apoptosis and Improves NPC Survival. The effect of melatonin on NPC cycle progression was analyzed using flow cytometric analysis. Cell cycle analysis revealed that melatonin at $<5 \mu \mathrm{M}$ dose-dependently increased the percentage of cells in the S-phase and decreased the G0/G1 populations compared with the control group, suggesting that melatonin affected the G0/G1 to $S$ phase transition (Figure $1(\mathrm{c})$ ). These data suggested that melatonin could promote cell cycle progression, which was consistent with the CCK-8 assay results. We next investigated the cell cycle-related protein levels in cells treated with various concentrations of melatonin using Western blot. The expression of the CDK2 and CDK4 proteins was increased, while the cyclin-dependent kinase inhibitors p21 and p27 were decreased in a dose-dependent manner (Figure 1(d)). Quantified analysis showed that melatonin at $1 \mu \mathrm{M}$ and $5 \mu \mathrm{M}$ showed a significant effect on the expression of the cell cycle-related proteins (Figure $1(\mathrm{e}), p<0.05$ ), while a slight but not significant increase of p 21 at a low concentration of melatonin $(0.1 \mu \mathrm{M})$ was observed (Figure $1(\mathrm{e}), p>0.05)$. These results were consistent with the G0/G1 population in the flow cytometric analysis.

In addition, we examined the role of melatonin in nucleus pulposus cell apoptosis and found that melatonin decreased the apoptosis of NPCs in a dose-dependent manner. Compared with the control group, a noticeable decrease of cell apoptosis was observed in the NPCs, which was significantly increased by cotreatment with $0.1,1$, and $5 \mu \mathrm{M}$ melatonin $(p<0.05$, Figure $1(\mathrm{f}))$. We also examined the apoptosis-related proteins by Western blot. In comparison 


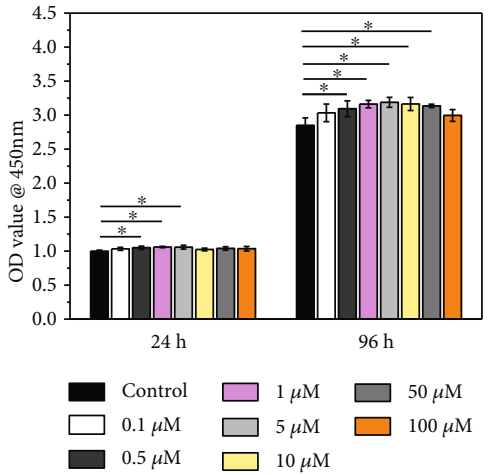

(a)
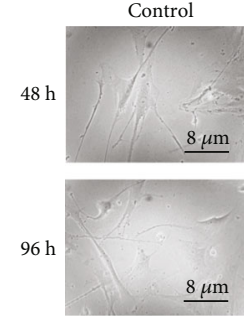

$0.1 \mu \mathrm{M}$
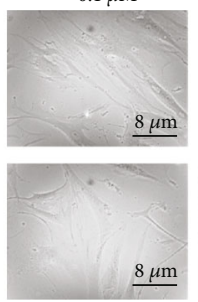
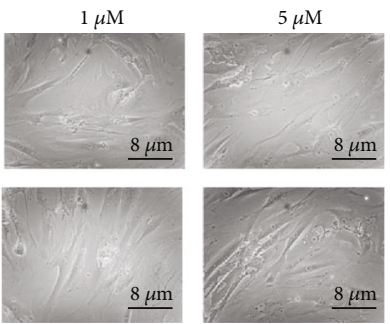

(b)

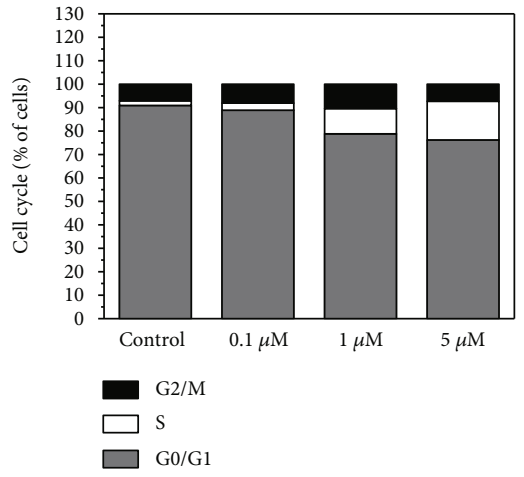

(c)

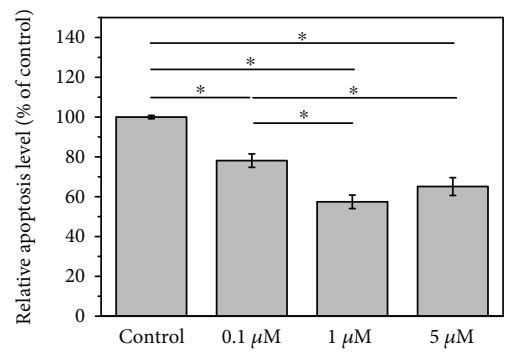

(f)

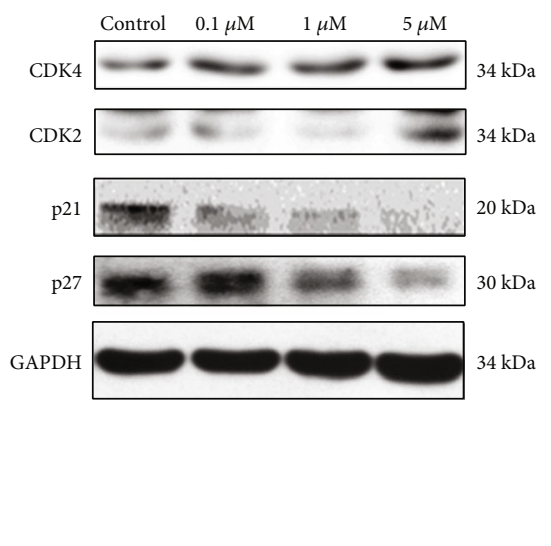

(d)

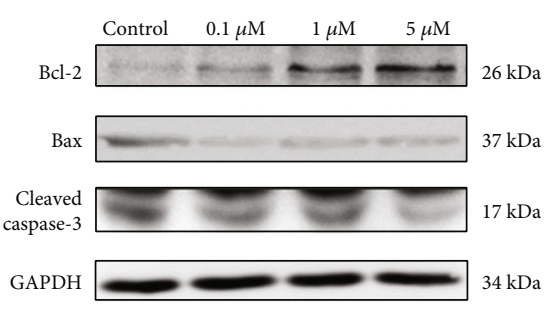

(g)

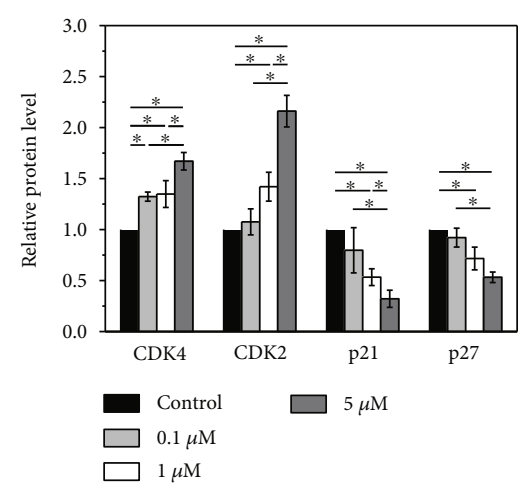

(e)

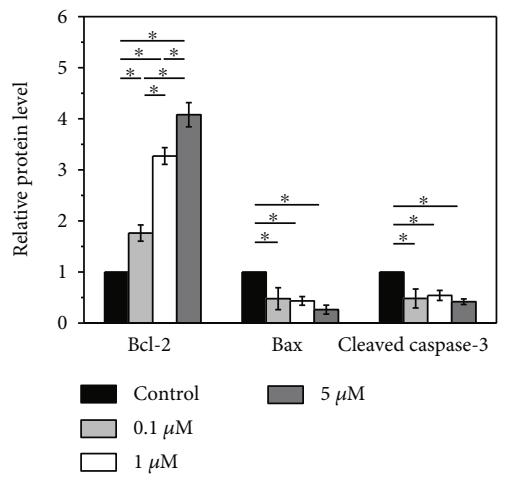

(h)

FIGURE 1: (a) Melatonin enhanced NPC viability. Cell viability of each group with $0.1,0.5,1,5,10,50$, and $100 \mu \mathrm{M}$ melatonin at both $24 \mathrm{~h}$ and $96 \mathrm{~h}$. Significant viability was observed in cells with melatonin treatment than that in untreated ones in both $24 \mathrm{~h}$ and $96 \mathrm{~h}\left({ }^{*} p<0.05\right.$ compared to the control group). (b) Melatonin alleviated the morphological changes in a dose-dependent manner. The cells were short and round in the control group. With increasing concentration, the changes to cell morphology were more obvious. Cells became bigger and long spindle shape. (c) Melatonin promoted the cell cycle progression. Melatonin-treated cells showed an increased percentage of cells in the S phase and decreased G0/G1 populations, a promoting of cell cycle progression in a dose dependent manner. (d) Western blot showed that the expression of the cell cycle-related proteins, CDK2 and CDK4, was increased, while p21 and p27 were decreased. (e) Quantified analysis of cell cycle-related protein Western blot result $\left({ }^{*} p<0.05\right)$. (f) Melatonin decreased the apoptosis of NPCs. A noticeable decrease of NPC apoptosis was observed, which was significantly promoted by cotreatment with $0.1,1$, and $5 \mu \mathrm{M}$ melatonin $\left({ }^{*} p<0.05\right)$. (g) Western blot showed that melatonin significantly ameliorated the expressions of apoptosis-related proteins, Bax and caspase-3, and it also induced the expression of Bcl-2. (h) Quantified analysis of apoptosis-related protein Western blot result $\left({ }^{*} p<0.05\right)$.

to the control group, melatonin decreased the expressions of Bax and active caspase- 3 proteins greatly; furthermore, melatonin had higher levels of the expression of $\mathrm{Bcl}-2$ protein. The Western blot and the corresponding quantified analysis further demonstrated that melatonin could significantly inhibit the apoptosis of NPCs to enhance their activity (Figures 1(g) and 1(h), $p<0.05)$.

3.4. Melatonin Protects NPCs from Degeneration. Furthermore, to determine the expression levels of matrix proteins 


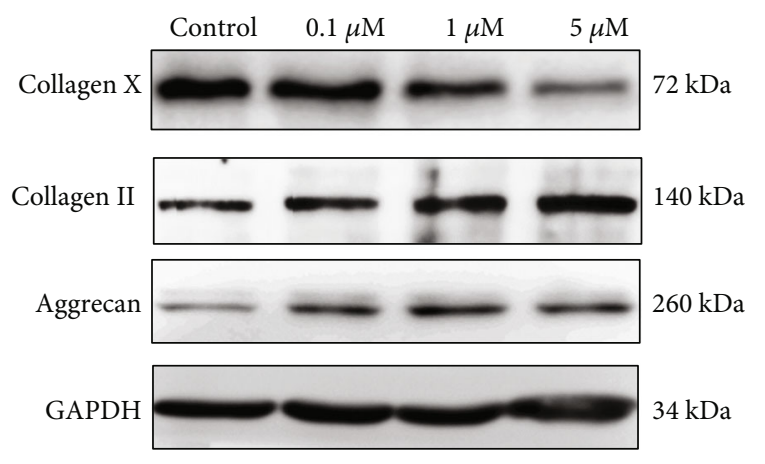

(a)

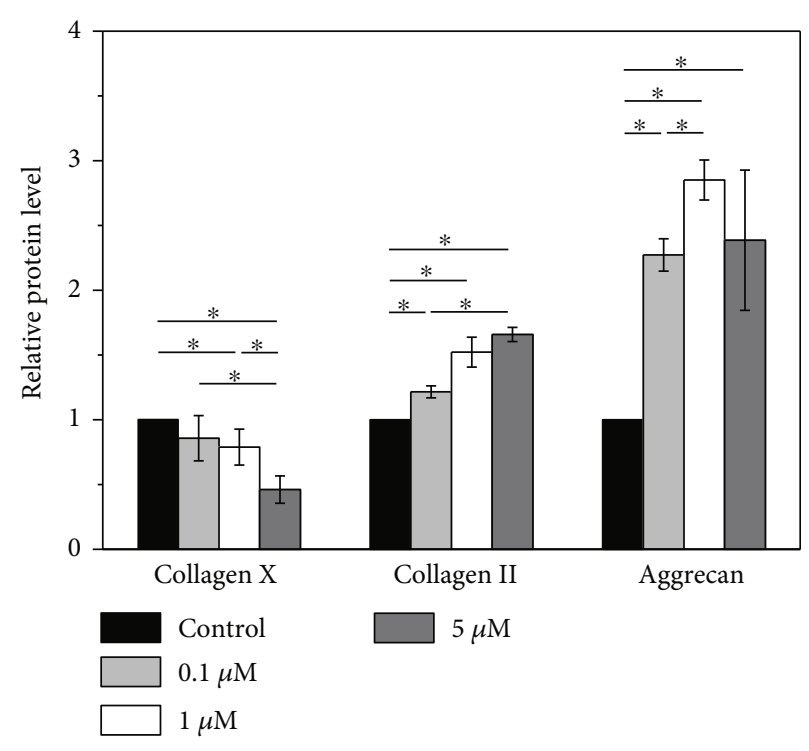

(b)

FIgURE 2: (a) Effect of melatonin to determine the expression levels of matrix proteins of NPCs using Western blot. The expression of collagen II and aggrecan proteins is increased and collagen X is decreased in NPCs when compared to the control. (b) Quantified analysis of Western blot result $\left({ }^{*} p<0.05\right)$.

of NPCs, Western blot analysis was applied. Collagen and aggrecan are the two major extracellular matrix components of intervertebral discs and have been shown to play critical roles in normal disc function. We found that melatonin dose-dependently increased the expression of collagen II and aggrecan and decreased that of collagen X (Figures 2(a) and $2(\mathrm{~b}), p<0.05)$. Thus, melatonin alleviated the degeneration of NPCs through modulation of the related proteins.

3.5. Melatonin Exerts Its Function via the ERK Pathway. To elucidate the mechanism by which melatonin regulates NPCs, the expression of key proteins in the NF- $\kappa \mathrm{B}$, ERK, and JNK signaling pathways was analyzed by Western blot. Melatonin significantly increased ERK1/2 activity above the concentration of $1 \mu \mathrm{M}$. Both the expression of ERK $1 / 2$ and phosphorylated ERK1/2 significantly increased after a treatment of high concentrations of melatonin. A slight inhibition of phosphorylated NF- $\kappa$ B protein expression was detected at $1 \mu \mathrm{M}$. A decrease in the phosphorylation level of NF- $\kappa \mathrm{B}$ was also found at high concentrations of melatonin, while no obvious change was observed in JNK activity after melatonin treatment (Figures 3(a)-3(c)). Thus, the ERK1/2 pathway was the most sensitive among the three pathways.

To further confirm the interaction between melatonin and ERK signaling pathway, we incubated NPCs with melatonin $(0$ and $5 \mu \mathrm{M})$ to investigate the role of melatonin in NPCs treated with or without an ERK1/2 inhibitor, U0126. Melatonin treatment alone increased the proportion of cells in the S-phase and decreased that of cells in the G0/G1 phase. In the presence of U0126, the effects of melatonin on cell cycle distribution (G0/G1 and $S$ phases) were reduced (Figure 3(d)). Similarly, melatonin alone reduced the expression of p21 and p27 and increased CDK2 and CDK4 levels in NPCs. Compared with melatonin-treated cells, the expres- sion of CDK2 and CDK4 was obviously reduced, while the expression of p21 and p27 was significantly increased in NPCs treated with melatonin and U0126 (Figure 3(f), $p<0.05$ ), while the expression of the cell cycle-related proteins of the melatonin and U0126 group has no significant differences compared with that of the control group (Figures 3(e) and 3(f), $p<0.05)$. After the treatment of U0126, the effects of melatonin on cell cycle protein expression are significantly weakened. Consistent with this phenomenon, flow cytometric analysis showed that there were no significant changes in terms of the apoptotic NPC percentages between the two groups after treatment with U0126 ( $p>0.05$ ), although the percentage in the melatonin group was significantly lower than that in the control group without an ERK1/2 inhibitor $(p<0.05)$ (Figure $3(\mathrm{~g})$ ). In addition, melatonin treatment inhibited the apoptosis of NPCs in the absence of U0126 by reducing the expression of Bax and cleaved caspase- 3 and increasing Bcl-2. However, the inhibition of apoptosis by melatonin was reversed upon addition of U0126 (Figures 3(h) and 3(i), $p<0.05$ ). Western blot analysis for the NPC matrix also showed that melatonin treatment increased the expression of collagen II and aggrecan and decreased that of collagen X levels. After the addition of U0126, U0126 had a significant weakened role on melatonin in the downregulation of collagen $\mathrm{X}$ expression, and there is no more positive effect from melatonin on aggrecan and collagen II expression in the NPCs (Figures $3(\mathrm{j})$ and $3(\mathrm{k}), p<0.05)$.

3.6. Melatonin Protects NPCs from Degeneration via the ERK Pathway in a Rabbit IDD Model. Furthermore, a rabbit lumbar intervertebral disc degeneration model was established to investigate the role of melatonin in intervertebral disc degeneration in vivo. All rabbits were subjected to T2WI sagittal 


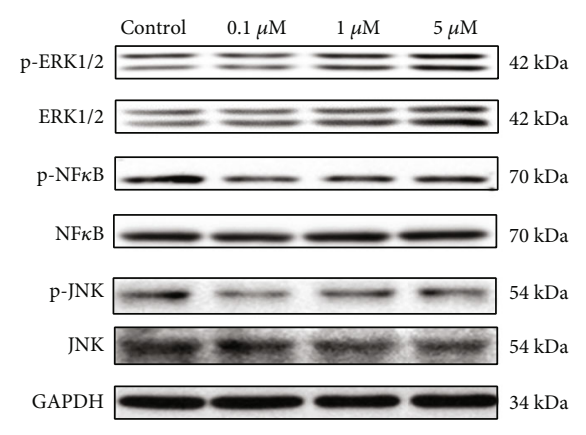

(a)

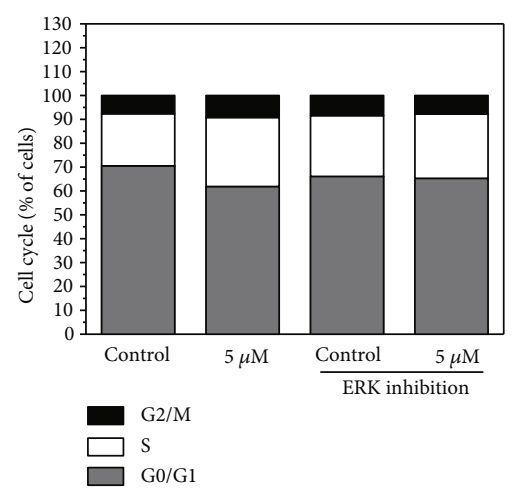

(d)

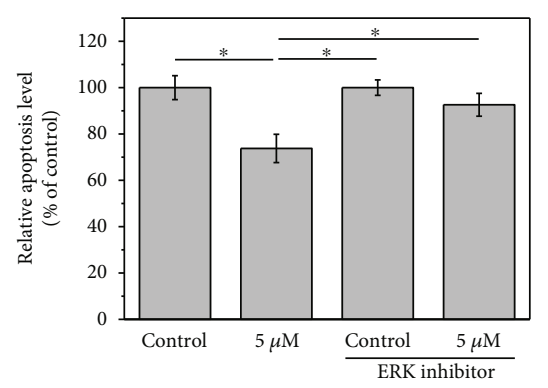

(g)

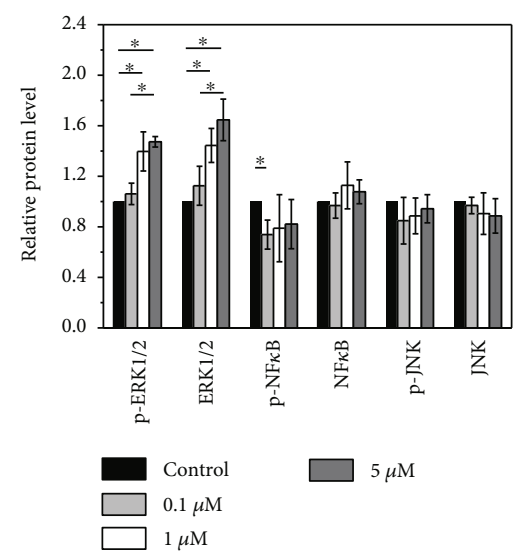

(b)

ERK inhibitor

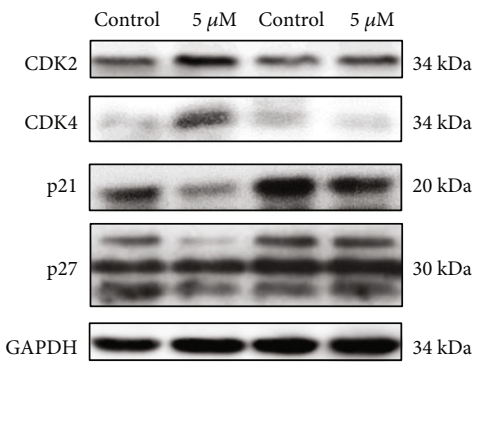

(e)

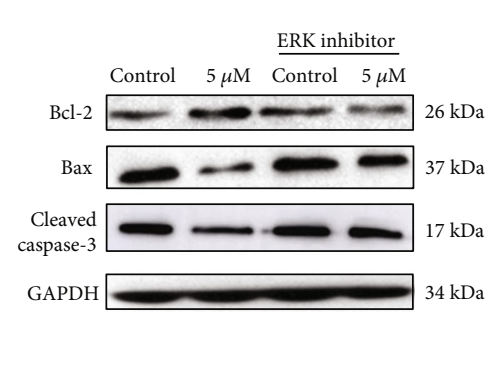

(h)

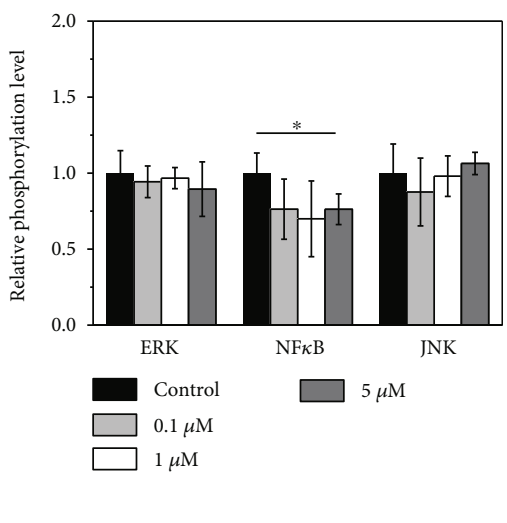

(c)

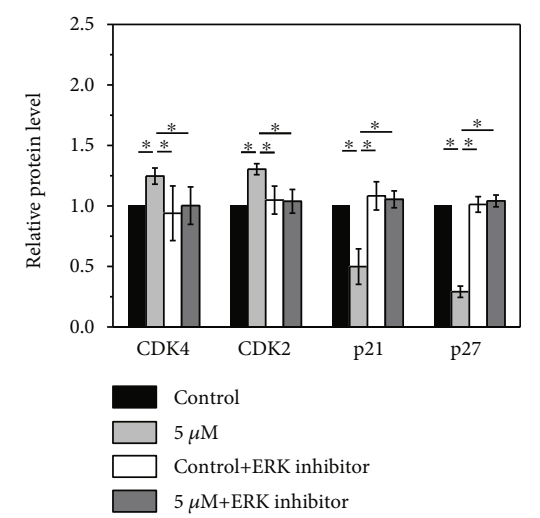

(f)

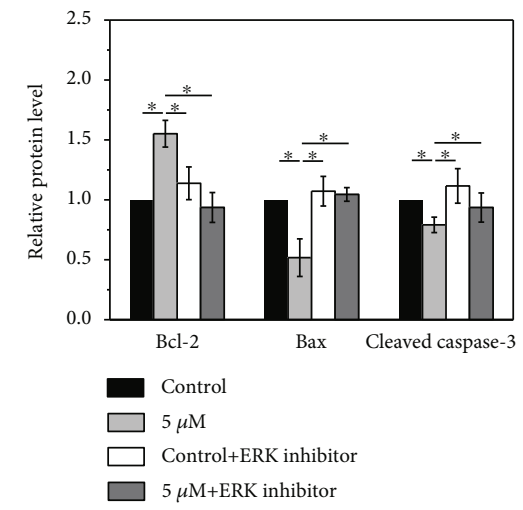

(i)

FIGURE 3: Continued. 


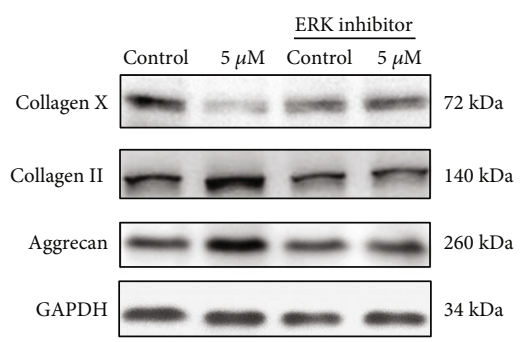

(j)

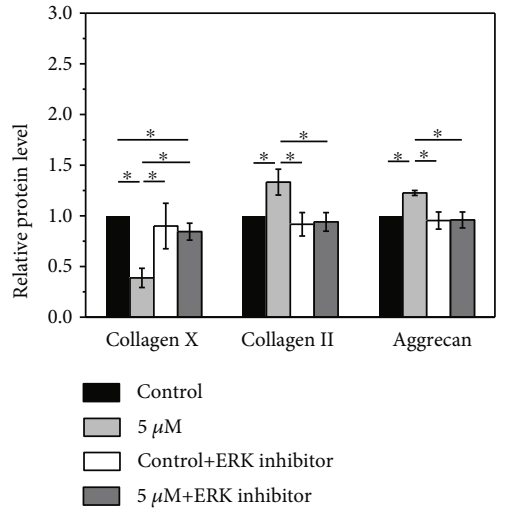

$(\mathrm{k})$

FIGURE 3: Melatonin, via the ERK pathway, regulates NPCs. (a-c) Melatonin significantly increased ERK1/2 activity above the concentration of $1 \mu \mathrm{m}$. A slight inhibition of phosphorylated NF- $\kappa$ B protein expression was detected at $1 \mu \mathrm{M}$. A decrease in phosphorylation level of NF- $\kappa \mathrm{B}$ was also found at high concentrations of melatonin. No obvious change was observed in JNK activity after melatonin treatment. (d) Melatonin increased the proportion of cells in the S-phase and decreased that of cells in the G0/G1 phase. With U0126, the effects on cell cycle distribution were reduced. (e) Similarly, the expression of the cell cycle-related proteins was reduced in NPCs treated with melatonin and U0126. (f) Quantified analysis of cell cycle-related protein Western blot result. (g, h) The inhibition of apoptosis by melatonin was also reversed upon addition of U0126. (i) Quantified analysis of apoptosis-related protein Western blot result. (j) Western blot analysis also showed that, after addition of U0126, U0126 had a significant weakened role on melatonin in the downregulation of collagen X expression and there is no more positive effect from melatonin on aggrecan and collagen II expression in the NPCs. (k) Quantified analysis of cell matrix protein Western blot result $\left({ }^{*} p<0.05\right)$.

scanning, and results showed that the intervertebral disc signals were obviously alleviated in the melatonin group compared with the rabbit in the degeneration group and the melatonin plus U0126 group (Figure 4(a)). Though the mean Thompson score of the melatonin group was lower than that of the saline group and the melatonin plus U0126 group, there was no obvious difference in the first 4 weeks after the injection. The Thompson scores of the melatonin group were significantly different from those of the saline group and the melatonin plus U0126 group $(p<0.05)$ in the eighth week (Figure 4(b)). In the saline group and the melatonin plus U0126 group, HE staining presented with shrunken nucleus pulposus in the intervertebral discs, reduced number of chondrocytes, and twisted or damaged annulus fibrosus. However, more chondrocytes with intact annulus fibrosus were observed in the melatonin-treated rabbits (Figure 4(c)). The intervertebral discs were also stained for the major proteins ERK1/2, collagen II, and collagen X to determine the function of the intervertebral discs. Injection of melatonin resulted in an increased expression of collagen II in the intervertebral discs, which was of higher intensity, in comparison to that of the melatonin plus U0126 and saline groups. By contrast, the staining for collagen $\mathrm{X}$ was weaker in the melatonin-treated group when compared with the melatonin plus U0126 and saline groups (Figures 4(c) and 4(d), $p<0.05)$. Compared with the two control groups, the melatonin group showed a significant increase in ERK1/2 according to immunohistochemical staining. This suggested that melatonin could activate the biological activity of ERK1/2, which effectively promotes the synthesis and secretion of main matrix components that contribute to the structural and functional recovery of intervertebral disc degeneration.

\section{Discussion}

The etiology of IDD is various, among which apoptosis is one of the most important. In 2001, for the first time, Ariga et al. revealed the positive correlation between apoptosis and IDD [23]. Many studies also indicated that apoptosis initiated the process of IDD [24-26].

Our study investigated the effect of melatonin on NPC behaviors and its underlying mechanism. Cell viability is an important factor for cell survival, which is also an important biological characteristic of IDD. We performed CCK-8 assay to detect NPC viability. Results clearly indicated that treatment with melatonin at different concentrations increased the viability of cells and retarded the morphological changes in the degenerated NPCs. The cell cycle is governed positively by cyclin/CDK complexes and negatively by CDKIs. The cyclin D/CDK4 and cyclin E/CDK2 complexes are required for cell cycle progression from the $\mathrm{G} 1$ phase to the $\mathrm{S}$ phase [27]. CDKIs, such as p21 and p27, inhibit cyclin/CDK activity, resulting in cell cycle arrest in the G0/G1 phase. Indeed, our results showed a dose-dependent increase in the percentage of cells in the $\mathrm{S}$ phase and a decrease of the percentage of NPCs in the G0/G1 phase after melatonin treatment by downregulation of CDK2 and CDK4 and upregulation of p21 and p27. The intrinsic apoptosis pathway is one of the two classic apoptosis pathways. In this pathway, caspase-3 plays an important role and can be activated by upstream effector proteins and induce the apoptosis cascade [28]. The $\mathrm{Bcl}-2$ family, including antiapoptotic protein $\mathrm{Bcl}-2$ and proapoptotic protein $\mathrm{Bax}$, is the central regulator in the mitochondrial apoptosis pathway [29]. In the present study, melatonin induced the expression levels of $\mathrm{Bcl}-2$ and reduced 


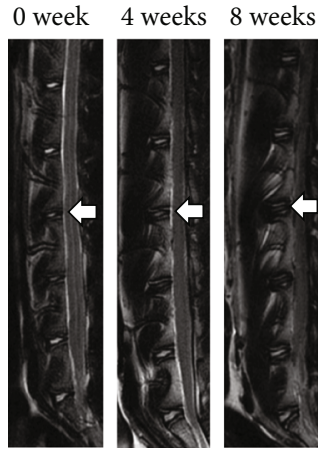

Melatonin

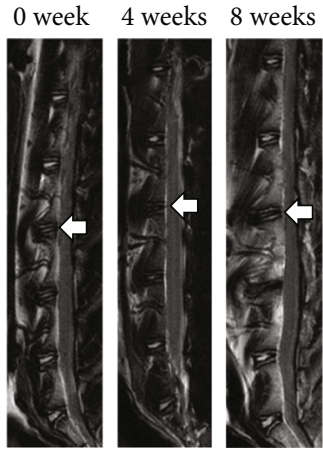

Melatonin+ERK inhibitor

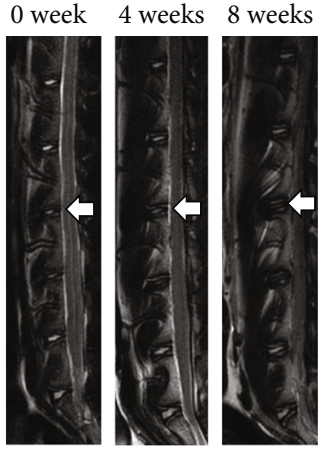

Saline

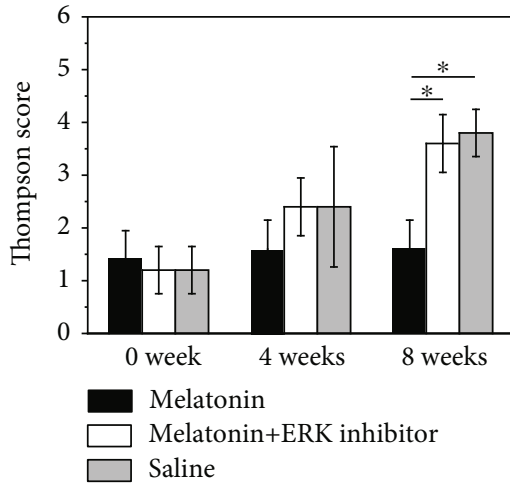

(b)

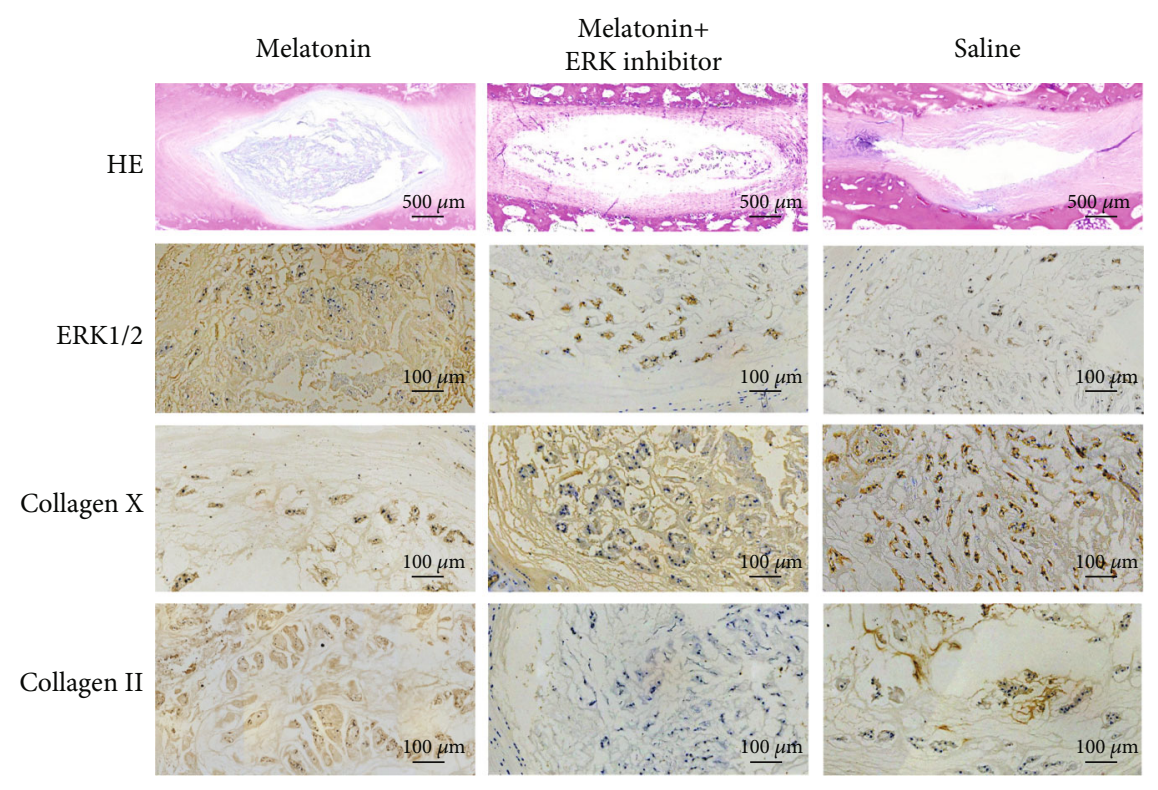

(c)

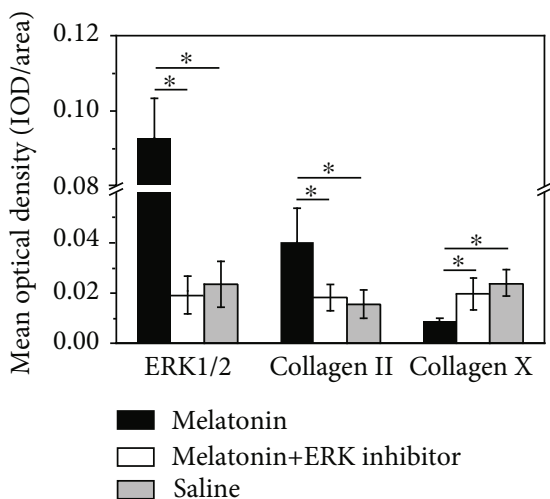

(d)

FIGURE 4: (a) Magnetic resonance imaging findings after melatonin injection on rabbit intervertebral discs. T2 signal intensity was stronger for the melatonin-injected discs than for the saline discs, including the melatonin plus U01256 group. (b) Thompson score showed the significant radiological improvement on the 8 th week brought by melatonin $\left({ }^{*} p<0.05\right)$. (c) Histological analysis on intervertebral discs by $\mathrm{HE}$ staining. More chondrocytes with intact annulus fibrosus were observed in the melatonin-treated rats. However, reduced number of chondrocytes and twisted or damaged annulus fibrosus presented in the two control groups. ERK $1 / 2$ immunohistochemical staining indicates that ERK 1/2 expression was more apparent in the melatonin group. Quantification of immunohistochemical staining showed that the melatonin group had significantly higher mean optical density than the inhibitor-treated and control groups. Collagen II and X immunohistochemical staining indicates that collagen II was detected in the melatonin-treated group, but little in the two control groups. By contrast, the staining for collagen X was weaker in the melatonin-treated group. Quantification of collagen II immunohistochemical staining showed that the melatonin-treated discs had significantly higher mean optical density than the control groups and the expression of collagen X was significantly lower. (d) Quantified analysis of immunohistochemical staining showed the significant histological improvement brought by melatonin via the ERK pathway $\left({ }^{*} p<0.05\right)$.

the expression of Bax in the NPCs, suggesting that melatonin induced antiapoptosis via the apoptotic caspase pathway.

As is well-known, apoptosis is regulated by a variety of intracellular signal transduction cascades. Mechanically, we examined the changes of three common apoptosis-related signaling pathways, NF- $\kappa \mathrm{B}, \mathrm{ERK}$, and JNK signaling pathways. Results showed that melatonin obviously increased ERK1/2 activity, slightly inhibited NF- $\kappa$ B activity, and had 
no effect on JNK expression. The mitogen-activated protein kinase (MAPK) signaling pathway is one of the most important signal transduction pathways and is found widely in cells [30]. Numerous studies have shown [31-34] that extracellular signaling-regulated kinase (ERK) pathway signal pathway, one of the subtypes of MAPK pathway, is a major participant in the regulation of cell growth, differentiation, and other functions. It participates in the extracellular signal transmission into the nucleus; through nuclear translocation, it transmits mitotic signals and activates transcription factors to promote cell proliferation and inhibit apoptosis [35]. The ERK pathway can be activated by inflammatory factors $[36,37]$ such as TNF- $\alpha$ and IL- 1 . The activation factors activate tyrosine kinase via cell membrane receptor. The signal was then passed to Ras and then activate Raf, MEK1/2 (MAPK/ERK kinase), and ERK1/2 sequentially [31, 38], regulating the transcription and expression of protein. Many studies have shown that the ERK pathway is involved in cell cycle regulation, especially the G1/S phase [39-41].

Recently, many studies have shown that the ERK signaling pathway plays an important role in IDD [6-9]. In 2005, Risbud et al. [42] found that rat NPCs could downregulate apoptosis by reducing the expression of apoptosis genes through the activation of ERK pathways. Pratsinis et al. [43] revealed that the proliferation of intervertebral disc cells can be enhanced by PDGF, bFGF, and IGF-I via ERK signaling pathways. Several studies have further proved that the ERK pathway is a potential target for the treatment of IDD and the activated ERK signal pathway can reverse or delay the process of IDD, which is consistent with the current study. Results showed that melatonin obviously increased ERK1/2 activity [44-47]. Given that melatonin elevated the expression of ERK1/2 in the NPCs, we thus speculated that melatonin could possibly activate the ERK1/2 signaling pathway to affect the function of NPCs. To confirm this hypothesis, the ERK1/2 pathway was blocked by the addition of an ERK1/2 inhibitor, U0126. Our results showed that the inhibition of ERK1/2 signals reversed the effect of melatonin on the activation of the cell cycle and apoptosis. Western blot analysis showed that the addition of the ERK inhibitor reduced the expression of collagen II and aggrecan, which were upregulated by melatonin and increased the expression of type X collagen, suggesting that U0126 aggravated the degeneration of NPCs. Therefore, our data suggest that the ERK1/2 signaling pathway mediates the effect of melatonin in the regulation of the biological processes of NPCs.

A recent work reported by Chen et al. [21] has well demonstrated the positive effect of melatonin on rat caudal tail IDD. However, the test and description for rat intervertebral disc are only about morphology. In addition, the rat tail disc degeneration model, which Chen used, has a quite different geometry and structure from human disc [48]. So, the mechanism underlying the effect of melatonin in the regulation of intervertebral discs was also confirmed in vivo by using a rabbit lumbar model of intervertebral disc degeneration, which has a more similar structure to human disc [48] and was induced by needle puncture. There are notochordal cells in the rabbit intervertebral disc, which is different from human adult NP cells. As a result, possible species-related differences in the response to melatonin should be considered. In the current study, we tried our best to avoid the effect of notochordal cells. On the one hand, rabbits have large numbers of notochordal cells at least until 12 months of age [49]. So one-year-old New Zealand white rabbits were selected for the study. On the other hand, the histology of the disc after puncture showed changes in the cell population from notochordal cells to chondrocytic cells [50]. So the injection was performed 4 weeks after the puncture. Four weeks after the injection, MRI examination revealed the delaying effect of melatonin in IDD. Melatonin injection retarded the degeneration of the intervertebral discs, which was finally confirmed by MRI and histological examination. However, combined treatment with an ERK1/2 signaling pathway inhibitor, U0126, reversed the protective role of melatonin in IDD.

Melatonin is a well-known neuroendocrine hormone secreted by the pineal body, which is implicated in the regulation of circadian and seasonal rhythms. Moreover, melatonin exhibits antitumor, antiosteoporosis, anti-inflammation, and antioxidation properties. In addition, melatonin has been used for hypnosis, anticancer therapy, anticardiovascular and cerebrovascular diseases, and antiaging [51-55]. In a preclinical study, melatonin was applied for osteoarthritis treatment for its ability to repair cartilage defects and promote cartilage regeneration. Moreover, melatonin presents a low toxicity and is a cheap agent with a wide range of applications. Melatonin has a synergistic effect when combined with other agents. Our study could provide the theoretical and experimental basis for the clinical application of melatonin by revealing the mechanism underlying its protective property against IDD for the very first time. This discovery opens up a new therapeutic approach for clinical treatment of IDD.

In summary, we conclude that melatonin affects the intervertebral discs in multiple ways. Melatonin increases the NPC viability through inhibition of cell cycle arrest and apoptosis, increases the secretion of functional factors to influence NPC physiological function, and finally retards cell degeneration. The current study provides the theoretical and experimental basis for developing a melatonin-based therapy for IDD via the ERK 1/2 signaling pathway.

\section{Data Availability}

The data that support the findings of this study are available from the corresponding author upon reasonable request.

\section{Conflicts of Interest}

All authors declare no conflicts of interest.

\section{Authors' Contributions}

Jun Ge and Quan Zhou contributed equally to the work.

\section{References}

[1] L. Madigan, A. R. Vaccaro, L. R. Spector, and R. A. Milam, "Management of symptomatic lumbar degenerative disk 
disease," The Journal of the American Academy of Orthopaedic Surgeons, vol. 17, no. 2, pp. 102-111, 2009.

[2] C. Cao, J. Zou, X. Liu et al., "Bone marrow mesenchymal stem cells slow intervertebral disc degeneration through the NF- $\kappa \mathrm{B}$ pathway," The Spine Journal, vol. 15, no. 3, pp. 530-538, 2015.

[3] H. Yang, C. Yuan, C. Wu et al., "The role of TGF- $\beta 1 / \mathrm{Smad} 2 / 3$ pathway in platelet-rich plasma in retarding intervertebral disc degeneration," Journal of Cellular Molecular Medicine, vol. 20, no. 8, pp. 1542-1549, 2016.

[4] H. Yang, C. Cao, C. Wu et al., "TGF- $\beta$ l suppresses inflammation in cell therapy for intervertebral disc degeneration," Scientific Reports, vol. 5, no. 1, article 13254, 2015.

[5] D. Simões, P. Riva, R. A. Peliciari-Garcia et al., "Melatonin modifies basal and stimulated insulin secretion via $\mathrm{NADPH}$ oxidase," The Journal of Endocrinology, vol. 231, no. 3, pp. 235-244, 2016.

[6] K. H. Park, J. W. Kang, E. M. Lee et al., "Melatonin promotes osteoblastic differentiation through the BMP/ERK/Wnt signaling pathways," Journal of Pineal Research, vol. 51, no. 2, pp. 187-194, 2011.

[7] C. Tocharus, Y. Puriboriboon, T. Junmanee, J. Tocharus, K. Ekthuwapranee, and P. Govitrapong, "Melatonin enhances adult rat hippocampal progenitor cell proliferation via ERK signaling pathway through melatonin receptor," Neuroscience, vol. 275 , pp. 314-321, 2014.

[8] J. H. Kim, S. J. Jeong, B. Kim, S. M. Yun, D. Y. Choi, and S. H. Kim, "Melatonin synergistically enhances cisplatin-induced apoptosis via the dephosphorylation of ERK/p90 ribosomal S6 kinase/heat shock protein 27 in SK-OV-3 cells," Journal of Pineal Research, vol. 52, no. 2, pp. 244-252, 2012.

[9] P.-O. Koh, "Melatonin attenuates the cerebral ischemic injury via the MEK/ERK/p90RSK/bad signaling cascade," Journal of Veterinary Medical Science, vol. 70, no. 11, pp. 1219-1223, 2008.

[10] K. Masuda, Y. Aota, C. Muehleman et al., "A novel rabbit model of mild, reproducible disc degeneration by an anulus needle puncture: correlation between the degree of disc injury and radiological and histological appearances of disc degeneration," Spine, vol. 30, no. 1, pp. 5-14, 2005.

[11] J. A. Roth, B. G. Kim, W. L. Lin, and M. I. Cho, "Melatonin promotes osteoblast differentiation and bone formation," Journal of Biological Chemistry, vol. 274, no. 31, pp. 22041-22047, 1999.

[12] H. Koyama, O. Nakade, Y. Takada, T. Kaku, and K. H. Lau, "Melatonin at pharmacologic doses increases bone mass by suppressing resorption through down-regulation of the RANKL-mediated osteoclast formation and activation," Journal of Bone Mineral Research, vol. 17, no. 7, pp. 1219-1229, 2002.

[13] N. Suzuki and A. Hattori, "Melatonin suppresses osteoclastic and osteoblastic activities in the scales of goldfish," Journal of Pineal Research, vol. 33, no. 4, pp. 253-258, 2002.

[14] N. M. Radio, J. S. Doctor, and P. A. Witt-Enderby, "Melatonin enhances alkaline phosphatase activity in differentiating human adult mesenchymal stem cells grown in osteogenic medium via MT2 melatonin receptors and the MEK/ERK (1/2) signaling cascade," Journal of Pineal Research, vol. 40, no. 4, pp. 332-342, 2006.

[15] M. Pei, F. He, L. Wei, and A. Rawson, "Melatonin enhances cartilage matrix synthesis by porcine articular chondrocytes," Journal of Pineal Research, vol. 46, no. 2, pp. 181-187, 2009.
[16] H. D. Lim, Y. S. Kim, S. H. Ko et al., "Cytoprotective and anti-inflammatory effects of melatonin in hydrogen peroxide-stimulated $\mathrm{CHON}-001$ human chondrocyte cell line and rabbit model of osteoarthritis via the SIRT1 pathway," Journal of Pineal Research, vol. 53, no. 3, pp. 225-237, 2012.

[17] M. Turgut, H. K. Başaloğlu, C. Yenisey, and Y. Ozsunar, "Surgical pinealectomy accelerates intervertebral disc degeneration process in chicken," European Spine Journal, vol. 15, no. 5, pp. 605-612, 2006.

[18] M. Turgut, G. Oktem, S. Uslu, M. E. Yurtseven, H. Aktuğ, and A. Uysal, "The effect of exogenous melatonin administration on trabecular width, ligament thickness and TGF- $\beta_{1}$ expression in degenerated intervertebral disk tissue in the rat," Journal of Clinical Neuroscience, vol. 13, no. 3, pp. 357-363, 2006.

[19] R. He, M. Cui, H. Lin et al., "Melatonin resists oxidative stressinduced apoptosis in nucleus pulposus cells," Life sciences, vol. 199, pp. 122-130, 2018.

[20] L. Zheng, X. Li, C. Chen, M. T. V. Chan, W. K. K. Wu, and J. Shen, "Melatonin inhibits nucleus pulposus (NP) cell proliferation and extracellular matrix (ECM) remodeling via the melatonin membrane receptors mediated PI3K-Akt pathway," Journal of Pineal Research, vol. 63, no. 3, article e12435, 2017.

[21] C. Yu, Y. Wu, H. Shi et al., "Melatonin ameliorates intervertebral disc degeneration via the potential mechanisms of mitophagy induction and apoptosis inhibition," Journal of Cellular Molecular Medicine, vol. 23, no. 3, pp. 2136-2148, 2019.

[22] J. Ge, H. Yang, Y. Chen, Q. Yan, C. Wu, and J. Zou, "PMMA bone cement acts on the Hippo/YAP pathway to regulate CTGF and induce intervertebral disc degeneration," ACS Biomaterials Science \& Engineering, vol. 5, no. 7, pp. 3293-3302, 2019.

[23] K. Ariga, S. Miyamoto, T. Nakase et al., "The relationship between apoptosis of endplate chondrocytes and aging and degeneration of the intervertebral disc," Spine, vol. 26, no. 22, pp. 2414-2420, 2001.

[24] D. Haschtmann, J. V. Stoyanov, P. Gédet, and S. J. Ferguson, "Vertebral endplate trauma induces disc cell apoptosis and promotes organ degeneration in vitro," European Spine Journal, vol. 17, no. 2, pp. 289-299, 2008.

[25] L. Jiang, X. Zhang, X. Zheng et al., “Apoptosis, senescence, and autophagy in rat nucleus pulposus cells: implications for diabetic intervertebral disc degeneration," Journal of Orthopaedic Research, vol. 31, no. 5, pp. 692-702, 2013.

[26] C. E. Heyde, S. K. Tschoeke, M. Hellmuth, A. Hostmann, W. Ertel, and A. Oberholzer, "Trauma induces apoptosis in human thoracolumbar intervertebral discs," BMC Clinical Pathology, vol. 6, no. 1, article 5, 2006.

[27] V. Andrés, "Control of vascular cell proliferation and migration by cyclin-dependent kinase signalling: new perspectives and therapeutic potential," Cardiovascular Research, vol. 63, no. 1, pp. 11-21, 2004.

[28] S. W. Fesik, "Promoting apoptosis as a strategy for cancer drug discovery," Nature Reviews Cancer, vol. 5, no. 11, pp. 876-885, 2005.

[29] X. Wang and Y. Wang, "Ginsenoside Rh2 mitigates pediatric leukemia through suppression of Bcl-2 in leukemia cells," Cellular Physiology and Biochemistry, vol. 37, no. 2, pp. 641-650, 2015.

[30] E. Herlaar and Z. Brown, "p38 MAPK signalling cascades in inflammatory disease," Molecular Medicine Today, vol. 5, no. 10 , pp. 439-447, 1999. 
[31] J. C. Chambard, R. Lefloch, J. Pouysségur, and P. Lenormand, "ERK implication in cell cycle regulation," Biochimica et Biophysica Acta (BBA) - Molecular Cell Research, vol. 1773, no. 8, pp. 1299-1310, 2007.

[32] T. Burdon, C. Stracey, I. Chambers, J. Nichols, and A. Smith, "Suppression of SHP-2 and ERK signalling promotes selfrenewal of mouse embryonic stem cells," Developmental Biology, vol. 210, no. 1, pp. 30-43, 1999.

[33] J. D. Weber, D. M. Raben, P. J. Phillips, and J. J. Baldassare, "Sustained activation of extracellular-signal-regulated kinase 1 (ERK1) is required for the continued expression of cyclin D1 in G1 phase," Biochemical journal, vol. 326, no. 1, pp. 61-68, 1997.

[34] J. N. Lavoie, G. L'Allemain, A. Brunet, R. Müller, and J. Pouysségur, "Cyclin D1 expression is regulated positively by the p42/p44MAPK and negatively by the p38/HOGMAPK pathway," Journal of Biological Chemistry, vol. 271, no. 34, pp. 20608-20616, 1996.

[35] V. Christen and K. Fent, "Silica nanoparticles induce endoplasmic reticulum stress response and activate mitogen activated kinase (MAPK) signalling," Toxicology reports, vol. 3, pp. 832-840, 2016.

[36] C. A. Séguin, R. M. Pilliar, J. A. Madri, and R. A. Kandel, "TNF- $\alpha$ induces MMP2 gelatinase activity and MT1-MMP expression in an in vitro model of nucleus pulposus tissue degeneration," Spine, vol. 33, no. 4, pp. 356-365, 2008.

[37] K. Wuertz, L. Quero, M. Sekiguchi et al., "The red wine polyphenol resveratrol shows promising potential for the treatment of nucleus pulposus-mediated pain in vitro and in vivo," Spine, vol. 36, no. 21, pp. E1373-E1384, 2011.

[38] B. Boilly, A. S. Vercoutter-Edouart, H. Hondermarck, V. Nurcombe, and X. Le Bourhis, "FGF signals for cell proliferation and migration through different pathways," Cytokine Growth Factor Reviews, vol. 11, no. 4, pp. 295-302, 2000.

[39] R. Hoshino, S. Tanimura, K. Watanabe, T. Kataoka, and M. Kohno, "Blockade of the extracellular signal-regulated kinase pathway induces marked G1 cell cycle arrest and apoptosis in tumor cells in which the pathway is constitutively activated: up-regulation of p27(Kip1)," Journal of Biological Chemistry, vol. 276, no. 4, pp. 2686-2692, 2001.

[40] M. F. Favata, K. Y. Horiuchi, E. J. Manos et al., "Identification of a novel inhibitor of mitogen-activated protein kinase kinase," The Journal of Biological Chemistry, vol. 273, no. 29, pp. 18623-18632, 1998.

[41] M. Kortylewski, P. C. Heinrich, M. E. Kauffmann, M. Böhm, A. MacKiewicz, and I. Behrmann, "Mitogen-activated protein kinases control p27/Kip1 expression and growth of human melanoma cells," Biochemical Journal, vol. 357, no. 1, pp. 297-303, 2001.

[42] M. V. Risbud, J. Fertala, E. J. Vresilovic, T. J. Albert, and I. M. Shapiro, "Nucleus pulposus cells upregulate PI3K/Akt and MEK/ERK signaling pathways under hypoxic conditions and resist apoptosis induced by serum withdrawal," Spine, vol. 30, no. 8, pp. 882-889, 2005.

[43] H. Pratsinis, V. Constantinou, K. Pavlakis, G. Sapkas, and D. Kletsas, "Exogenous and autocrine growth factors stimulate human intervertebral disc cell proliferation via the ERK and Akt pathways," Journal of Orthopaedic Research, vol. 30, no. 6, pp. 958-964, 2012.

[44] D. Mi, C. Cai, B. Zhou et al., "Long non-coding RNA FAF1 promotes intervertebral disc degeneration by targeting the
Erk signaling pathway," Molecular Medicine Reports, vol. 17, no. 2, pp. 3158-3163, 2018.

[45] D. Ye, L. Dai, Y. Yao et al., "miR-155 inhibits nucleus pulposus cells' degeneration through targeting ERK 1/2," Disease markers, vol. 2016, Article ID 6984270, 7 pages, 2016.

[46] M. V. Risbud, A. Di Martino, A. Guttapalli et al., "Toward an optimum system for intervertebral disc organ culture: TGFbeta 3 enhances nucleus pulposus and anulus fibrosus survival and function through modulation of TGF-beta-R expression and ERK signaling," Spine, vol. 31, no. 8, pp. 884-890, 2006.

[47] H. Yang, F. Gao, X. Li, J. Wang, H. Liu, and Z. Zheng, "TGF- $\beta 1$ antagonizes TNF- $\alpha$ induced up-regulation of matrix metalloproteinase 3 in nucleus pulposus cells: role of the ERK1/2 pathway," Connective Tissue Research, vol. 56, no. 6, pp. 461468, 2015.

[48] G. D. O’Connell, E. J. Vresilovic, and D. M. Elliott, "Comparison of animals used in disc research to human lumbar disc geometry," Spine, vol. 32, no. 3, pp. 328-333, 2007.

[49] C. J. Hunter, J. R. Matyas, and N. A. Duncan, "Cytomorphology of notochordal and chondrocytic cells from the nucleus pulposus: a species comparison," Journal of Anatomy, vol. 205, no. 5, pp. 357-362, 2004.

[50] M. Alini, S. M. Eisenstein, K. Ito et al., "Are animal models useful for studying human disc disorders/degeneration?," European Spine Journal, vol. 17, no. 1, pp. 2-19, 2008.

[51] Y. Tong, H. Huang, and H. Pan, "Inhibition of MEK/ERK activation attenuates autophagy and potentiates pemetrexedinduced activity against HepG2 hepatocellular carcinoma cells," Biochemical Biophysical Research Communications, vol. 456, no. 1, pp. 86-91, 2015.

[52] S. Tordjman, S. Chokron, R. Delorme et al., "Melatonin: pharmacology, functions and therapeutic benefits," Current Neuropharmacology, vol. 15, no. 3, pp. 434-443, 2017.

[53] Y. Uyanikgil, T. Cavusoglu, K. D. Kilıc et al., "Useful effects of melatonin in peripheral nerve injury and development of the nervous system," Journal of Brachial Plexus Peripheral Nerve Injury, vol. 12, no. 1, pp. e1-e6, 2017.

[54] M. Permuy, M. López-Peña, A. González-Cantalapiedra, and F. Muñoz, "Melatonin: a review of its potential functions and effects on dental diseases," International journal of molecular sciences, vol. 18, no. 4, p. 865, 2017.

[55] P. Wongprayoon and P. Govitrapong, "Melatonin as a mitochondrial protector in neurodegenerative diseases," Cellular Molecular Life Sciences, vol. 74, no. 21, pp. 3999-4014, 2017. 


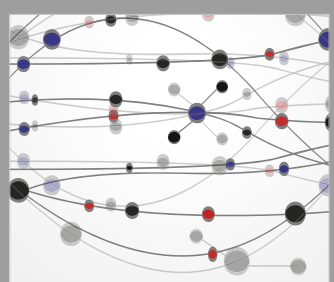

The Scientific World Journal
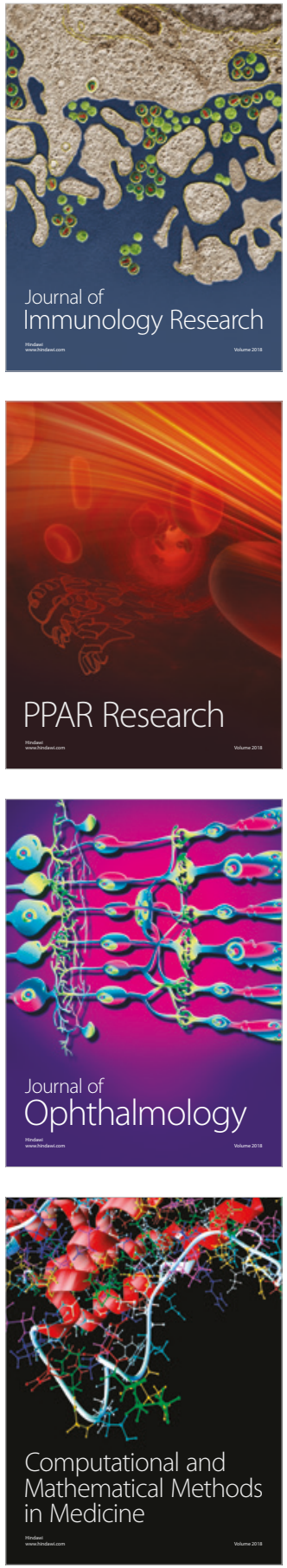

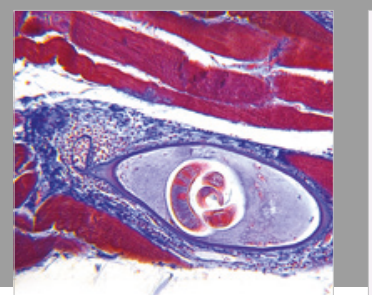

Gastroenterology Research and Practice

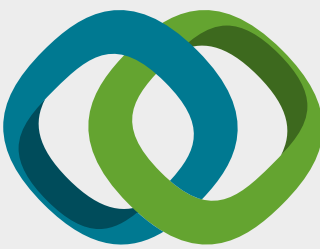

\section{Hindawi}

Submit your manuscripts at

www.hindawi.com
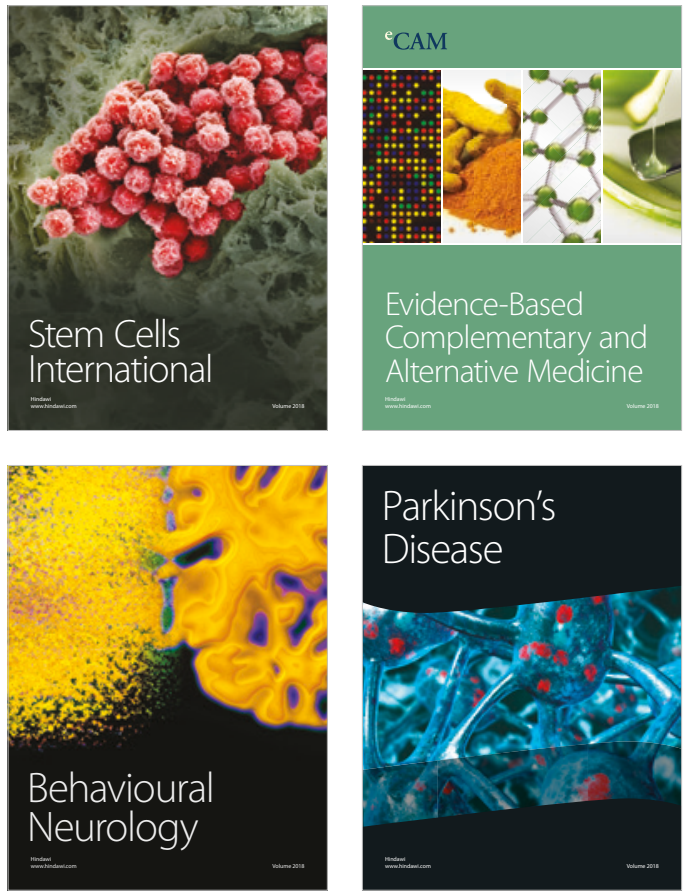

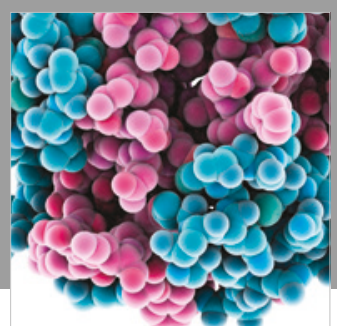

ournal of

Diabetes Research

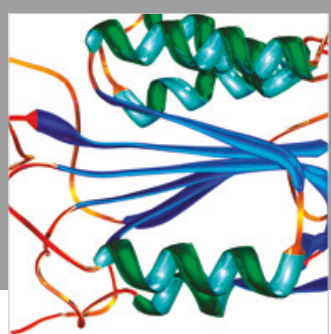

Disease Markers
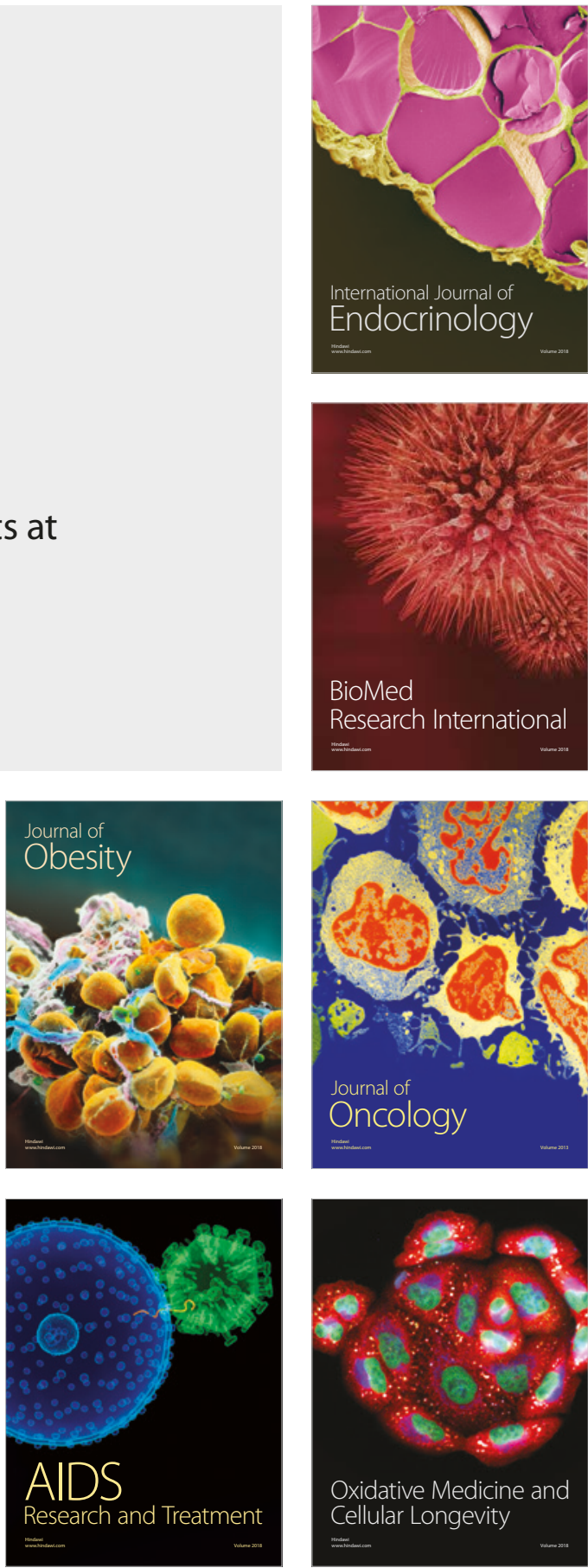